\title{
Acoustic environmental problems at temporary shelters for victims of the Mid-Niigata Earthquake
}

\author{
Koji Nagahata $^{1, *}$, Norio Suzuki ${ }^{1, \dagger}$, Megumi Sakamoto ${ }^{1, \ddagger}$, \\ Fuminori Tanba ${ }^{1, \S}$, Shin-ya Kaneko, ${ }^{2,}$ and Tetsuhito Fukushima ${ }^{2, \|}$ \\ ${ }^{1}$ Fukushima University, \\ 1 Kanayagawa, Fukushima, 960-1296 Japan \\ ${ }^{2}$ Fukushima Medical University, \\ 1 Hikarigaoka, Fukushima, 960-1295 Japan
}

(Received 19 April 2007, Accepted for publication 23 May 2007)

Keywords: The Mid-Niigata earthquake, Temporary shelters for victims, Acoustic environmental problems PACS number: 43.50.Qp [doi:10.1250/ast.29.99]

\section{Introduction}

An earthquake on October 23, 2004 inflicted heavy damage on the Mid-Niigata district. The earthquake severed all the roads to Yamakoshi village from neighboring cities: the village was isolated. Consequently, all the village residents were forced to evacuate to temporary shelters in neighboring Nagaoka city for two months, before they moved to temporary houses [1].

The shelters for the village people were gymnasiums and buildings with large separated rooms similar to community centers, as mentioned in the next section: they were not originally designed for use as temporary shelters. Therefore, it seems that there were several problems, including acoustical problems, in their lives as evacuees. In those problems, some could be prevented by proper preparation. Furthermore, revealing the problems may lead to more suitable designs for the temporary shelters.

In this context, a questionnaire survey and interviews among Yamakoshi residents were conducted to elucidate problems regarding the living environment at the temporary shelters. In this study, we analyzed acoustic environmental problems there. In particular, this paper mainly focuses on the differences in the acoustic environmental problems between two types of temporary shelters.

\section{About temporary shelters}

Eight facilities were used for the temporary shelters for the Yamakoshi resident victims: two high school gymnasiums, four high school seminar houses, one community center, and one facility for the elderly. Of these shelters, the facility for the elderly was only for elders who required nursing care and their families, and therefore the main temporary shelters comprised the other seven facilities.

The seven main temporary shelters were divided into

\footnotetext{
*e-mail: nagahata@sss.fukushima-u.ac.jp

†e-mail: norio@ads.fukushima-u.ac.jp

†e-mail: sakamoto@ads.fukushima-u.ac.jp

§e-mail: tanba@ads.fukushima-u.ac.jp

e-mail: s-kaneko@fmu.ac.jp

"e-mail: t-fuku@fmu.ac.jp
}

two types: two gymnasiums and five buildings with large separated rooms similar to community centers. The high school gymnasiums had no stands, and all victims used the floor. The sizes of the gymnasiums were almost equivalent to two basketball courts. The floor type of the large rooms used for the temporary shelters differed; some had tatami-covered floors and others had vinyl flooring. Also, the size of the rooms differed. The space allotted to each victim was about one tatami mat (approximately $1.7 \mathrm{~m}^{2}$ ) regardless of the shelter type.

Initially, the Yamakoshi residents were evacuated to these shelters at random. After 10 days, they moved to the shelter designated for their particular local community. After the move, the two gymnasiums were occupied by the residents of two of the largest communities, and the other five main shelters were occupied by those of the smaller communities. The number of evacuees held by the two gymnasiums were 358 and 289, respectively, and those for the other five main shelters were 170, 137, 131, 114 and 94, respectively, immediately after the move.

\section{Outline of the survey}

A questionnaire survey and interviews were conducted to elucidate the problems related to the living environment at the temporary shelters.

The questionnaire consisted of three parts. The first part consisted of questions about the individual attributes of the respondents, such as gender, age, family structure, and earthquake damage. The second part consisted of questions about their lives as evacuees, including problems, their health condition, and stressful experiences at temporary shelters and temporary houses. The last part consisted of questions about the future life planning of the respondents. This study focuses on the responses to the questions asked in the second part of the questionnaire about problems with the living environment and stressful experiences at the temporary shelters.

Regarding the questions about problems with the living environment at the temporary shelters, respondents were asked whether they had experienced any of the problems shown in Table 1. In the same way, respondents were asked the questions about problems with the living environment at the temporary houses. 
Table 1 Problems with the living environment.

Size problems (about the allotted space for each victim)

Temperature problems

Illumination problems

Acoustical environment problems

Odor problems

Bathing facility problems

Lavatory problems

Problems related to other equipment

Problems related to privacy

Table 2 Questions related to stressful experiences.

Whether respondents felt uneasy.

Whether respondents felt unpleasant.

Whether respondents felt stressed.

Whether respondents felt difficulty with respect

to social matters.

Regarding the questions about stressful experiences, respondents were asked the four questions listed in Table 2.

The interviews were conducted on the basis of the responses to the questionnaire survey. Regarding this paper, respondents were asked more concretely about the problems they had cited in the questionnaire.

The survey procedure was as follows. First, inquirers visited each respondent's temporary house and explained the aims of the survey. Then each respondent answered the questionnaire. Finally, each respondent took part in the interview. In some cases, such as when a respondent was farsighted, the questionnaire survey was conducted in an interview style. In such cases, the questionnaire survey and interview were merged. Furthermore, some respondents only responded to the questionnaire survey because of temporal restrictions. In such cases, respondents were asked to describe any concrete problems they had experienced while living in the shelters in the white spaces of the questionnaire sheets.

The survey was conducted on August 23 and 24, 2005. The respondents were those residents of the temporary housings constructed for Yamakoshi residents who were present at the time of the survey. In order to obtain as great a variety of respondents as possible, selection of the respondents was coordinated, taking gender and age into consideration.

Valid responses were obtained from 84 to 87 respondents, depending on the questions. The response rates were $88.4 \%$ to $91.6 \%$. The composition of the respondents with respect to gender and age are shown in Table 3.

The inquirers were four faculty members and four students of Fukushima University along with a researcher and eight students of Fukushima Medical University. All of the inquirers from Fukushima University had participated in volunteer activities for the Yamakoshi resident earthquake victims.

\section{Results and discussion}

4.1. Differences in noise sensitivity between refugees of both temporary shelter types

First of all, the difference in noise sensitivity between
Table 3 Composition of the respondents' gender and age.

\begin{tabular}{|c|c|c|c|}
\hline \multirow{2}{*}{ Age } & \multicolumn{2}{|c|}{ Gender } & \multirow{2}{*}{ Total } \\
\hline & Male & Female & \\
\hline-19 & 1 & 0 & 1 \\
\hline $20-29$ & 3 & 1 & 4 \\
\hline $30-39$ & 2 & 1 & 3 \\
\hline $40-49$ & 5 & 2 & 7 \\
\hline $50-59$ & 4 & 11 & 15 \\
\hline 60-69 & 10 & 16 & 26 \\
\hline 70-79 & 9 & 11 & 20 \\
\hline $80-$ & 4 & 7 & 11 \\
\hline Total & 38 & 49 & 87 \\
\hline
\end{tabular}

refugees of the gymnasiums and those of the buildings resembling community centers was analyzed. For this purpose, the frequencies of complaints regarding problems with the acoustic environments of the temporary houses were compared between both temporary shelter types: the specifications and geographical conditions of the temporary houses were similar for all refugees except for the size of the houses, as they depended on the household compositions of the refugees.

As a result, the frequency of complaints from the refugees of the gymnasiums were $23(46.0 \%)$, and that from the refugees of the buildings resembling community centers were $11(32.4 \%)$ : a chi-square test shows that this result was not statistically significant $(p=0.26)$. This means that the noise sensitivities of both refugee groups were not different. Therefore, we can say that the differences in the responses to the acoustic environments of the temporary shelters between both refugee groups shown below originate from the differences in the acoustical environments between both shelter types.

4.2. Problems with the living environment at the temporary shelters

The numbers and percentages of complaints reported regarding the living environment from all respondents are shown in Table 4. As this table shows, problems about the acoustical environment were reported by 40 respondents (46.0\%). This was the sixth most frequently cited environmental problem at the temporary shelters.

Table 5 shows the number of complaints about the living environment for each shelter type. As this table shows, the ratios of complaints about the acoustical environment were different depending on the type of shelter, and these differences were statistically significant $(p<0.01)$. Furthermore, the order of frequency of complaints was also different depending on the type of shelter: problems with the acoustic environment were the third most frequently cited problems at the gymnasiums, while they were the fifth most frequently cited problems at the buildings resembling community centers.

These results suggest that the acoustical environments of the gymnasiums were worse than those of the buildings resembling community centers. 
Table 4 Number of complaints regarding the living environment at the temporary shelters (All respondents).

\begin{tabular}{lc}
\hline \multicolumn{1}{c}{ Problems } & $n$ \\
\hline Size problems & $57(66.3 \%)$ \\
Problems related to privacy & $42(48.8 \%)$ \\
Bathing facility problems & $42(48.8 \%)$ \\
Temperature problems & $41(47.1 \%)$ \\
Lavatory problems & $40(46.5 \%)$ \\
Acoustical environment problems & $40(46.0 \%)$ \\
Problems related to other equipment & $24(28.6 \%)$ \\
Odor problems & $20(23.0 \%)$ \\
Illumination problems & $15(17.2 \%)$ \\
\hline
\end{tabular}

Table 5 Number of complaints regarding the living environment at the temporary shelters (classified by shelter type).

\begin{tabular}{|c|c|c|c|}
\hline \multirow[b]{2}{*}{ Problems } & \multicolumn{2}{|c|}{ Shelter type } & \multirow[b]{2}{*}{$\chi^{2}$ test } \\
\hline & Gymnasium & $\begin{array}{l}\text { Community } \\
\text { center }\end{array}$ & \\
\hline Size problems & $36(73.5 \%)$ & $20(57.1 \%)$ & n.s. \\
\hline Temperature problems & $29(58.0 \%)$ & $12(34.3 \%)$ & $p<0.05$ \\
\hline Illumination problems & $10(20.0 \%)$ & $5(14.3 \%)$ & n.s. \\
\hline $\begin{array}{l}\text { Acoustical environment } \\
\text { problems }\end{array}$ & $30(60.0 \%)$ & $10(28.6 \%)$ & $p<0.01$ \\
\hline Odor problems & $16(32.0 \%)$ & $4(10.3 \%)$ & $p<0.05$ \\
\hline Bathing facility problems & $27(55.1 \%)$ & $15(42.9 \%)$ & n.s. \\
\hline Lavatory problems & $28(57.1 \%)$ & $12(34.3 \%)$ & $p<0.05$ \\
\hline $\begin{array}{l}\text { Problems related } \\
\text { to other equipment }\end{array}$ & $17(35.4 \%)$ & $6(16.8 \%)$ & n.s. \\
\hline Problems related to privacy & $32(59.3 \%)$ & $9(26.5 \%)$ & $p<0.01$ \\
\hline
\end{tabular}

4.3. Specific problems regarding the acoustic environment

In the interviews, 25 respondents described specific problems with the acoustic environment. Table 6 shows an itemized list of the responses.

Complaints about the clamor of children and crying babies were cited frequently by the respondents irrespective of the type of the shelter to which they had been evacuated. Regarding these complaints, some mothers responded that they were mentally fatigued because their children made noise in the temporary shelters and that it might bother the other refugees.

In addition, the voices of other refugees were also cited by respondents irrespective of the type of shelter to which they had been evacuated. Voices heard after lights-out especially caused annoyances.

However, the other serious complaints were only indicated by respondents who had evacuated to the gymnasiums. The responses for "General annoyance at shelters," shown in Table 6, indicated that the general impressions of the shelters, and not specific sounds, were what caused the respondents to feel that the shelters were noisy and annoying.

Footsteps in the gymnasiums generally made loud sounds. Worse still, the refugees slept on thin mats or blankets spread on the floor. In this situation, footsteps became a problem especially at bedtime because they disturbed the refugees' sleep.
Table 6 Number of complaints regarding specific problems with the acoustical environment.

\begin{tabular}{lccc}
\hline \multirow{2}{*}{\multicolumn{1}{c}{ Specific problems }} & \multicolumn{2}{c}{ Shelter type } \\
\cline { 2 - 3 } & Gymnasiums & $\begin{array}{l}\text { Community } \\
\text { centers }\end{array}$ & \\
\hline Clamor of children & 6 & 4 & 10 \\
(including crying babies) & 5 & 1 & 6 \\
Voices of other refugees & 4 & 0 & 4 \\
General annoyance at shelters & 4 & 0 & 4 \\
Footsteps of refugees & 2 & 1 & 3 \\
(especially at night) & 2 & 0 & 2 \\
Snoring & 1 & 1 & 2 \\
Sound of televisions & 2 & 0 & 2 \\
Environmental noises & 0 & 1 & 1 \\
Coughing & & & \\
Sounds of doors & & &
\end{tabular}

Table 7 Relationship between complaints about acoustic environmental problems and the stress experiences.

\begin{tabular}{|c|c|c|c|}
\hline \multirow[b]{2}{*}{$\begin{array}{l}\text { Complained } \\
\text { stress experiences }\end{array}$} & \multicolumn{2}{|c|}{ Acoustic environmental problem } & \multirow[b]{2}{*}{$\chi^{2}$ test } \\
\hline & $\begin{array}{c}\text { Complained } \\
n\end{array}$ & $\begin{array}{c}\text { No complaint } \\
n\end{array}$ & \\
\hline Uneasiness & $33(86.6 \%)$ & $22(47.8 \%)$ & $p<0.001$ \\
\hline Unpleasantness & $27(69.2 \%)$ & $7(15.2 \%)$ & $p<0.001$ \\
\hline Feel stressed & $31(77.5 \%)$ & $12(26.1 \%)$ & $p<0.001$ \\
\hline $\begin{array}{l}\text { Difficulty with } \\
\text { social matters }\end{array}$ & $15(38.5 \%)$ & $6(13.0 \%)$ & $p<0.05$ \\
\hline
\end{tabular}

Ratios in this table show the ratios to respondents who complained (or did not complain) about acoustic environmental problem respectively.

A television was set up at each temporary shelter. In order for many people to watch television together, the volume of the television had to be set at a high level. Therefore, the refugees located near the television were annoyed.

In this way, the acoustical environments of the gymnasiums can be considered to be worse than those of the buildings resembling community centers from the point of view of the variety of problems.

4.4. Relationship between complaints about acoustic environmental problems and stressful experiences

Finally, the relationship between complaints about the acoustic environment and stressful experiences was analyzed. Table 7 shows the results.

As this table shows, the proportion of the participants who complained about the acoustic environment of the temporary shelters and had stressful experiences was higher than that of those who did not complain about the acoustic environment. These tendencies were statistically significant.

Paying attention to other living environment factors, not all environmental factors had statistically significant relationships with the stressful experiences. For example, problems with illumination, lavatory facilities, and privacy had statistically significant relationships with uneasiness, unpleasantness, and difficulty with social matters. However, complaints about the size of the space and temperature only had a 
statistically significant relationship with unpleasantness, while complaints about odors only had a statistically significant relationship with feeling stressed.

These results indicate that dissatisfaction with the acoustical environment of the temporary shelters is connected to many kinds of stressful experiences when compared to other living environment factors. Therefore, although further analysis on the relationship between complaints about the acoustic environment and stressful experiences will be needed, it seems reasonable to suppose that improvements to the acoustic environment of temporary shelters should lead to some mitigation of refugees' stress.

\section{Conclusions}

In this study, acoustic environmental problems of the temporary shelters used for the victims of the Mid-Niigata Earthquake were analyzed. Results indicated that the acoustical environments of the gymnasiums were worse than those of the buildings resembling community centers: complaints about the acoustic environment were more frequent at the gymnasiums; furthermore, gymnasiums had unique serious noise-related problems.

Moreover, the respondents who complained about the acoustic environment tended to have more stressful experiences at the temporary shelters.

In conclusion, buildings resembling community centers are more recommendable as temporary shelters than gymnasiums, at least from the perspective of noise problems.

\section{Acknowledgments}

The authors express their sincere appreciation to all the participants for their cooperation in this study. This study was supported by the Ministry of Education, Culture, Sports, Science and Technology, Grant-in-Aid for Scientific Research (B), No. 17310089, 2005-2006.

\section{Reference}

[1] Niigata Nippo and Broadcasting System of Niigata Inc., 10.23 Mid-Niigata Earthquake: A Chronicle of the One Year (Niigata Nippo, Niigata, 2005). 